\title{
FORMAÇÃO DE PROFESSORES E SEUS SABERES DISCIPLINARES EM ASTRONOMIA ESSENCIAL NOS ANOS INICIAIS DO ENSINO FUNDAMENTAL
}

RESUMO: Este artigo apresenta parte dos resultados de uma pesquisa mais ampla acerca da Educação em Astronomia na formação de professores dos anos iniciais do ensino fundamental. A partir da análise dos principais tópicos em Astronomia trabalhados nacionalmente e dos resultados de pesquisas da área, identificamos um conjunto de conteúdos fundamentais em Astronomia para o trabalho docente. Por meio da investigação por amostragem de professores, porém, demonstramos que, mesmo nestes conteúdos essenciais, há a persistência de concepções alternativas por parte dos docentes. Os resultados apontam, assim, para a necessidade de uma melhoria na qualificação docente em relação aos seus saberes disciplinares, embasada em resultados de pesquisas sobre Educação em Astronomia, a favor de um ensino que contemple, no mínimo, os conteúdos fundamentais sobre este tema.

Palavras-chave: Educação em Astronomia; Formação de Professores; Conteúdos Disciplinares Essenciais.

\section{TEACHER'S EDUCATION AND THEIR DISCIPLINARY KNOWLEDGE OF ESSENTIAL ASTRONOMY FOR THE FIRST YEARS OF PRIMARY SCHOOL}

ABSTRACT: This paper presents some outcomes of a broader research on Astronomy Education in primary school teacher's education. From the analysis of the main astronomy subjects thought nationwide and the research outcomes, we identified a set of astronomy contents considered fundamental to the teachers practice. Through a research carried out among a sample of primary school teachers, however, we show that, even in these essential contents, persists alternative conceptions among those teachers. Data collected pointed out, thus, to the necessity of improving teacher's education in this area, taking into consideration astronomy education research outcomes, in favor of a teaching which contemplates, at least, the fundamental contents on this subject.

Keywords: Astronomy Education; Teacher's Education; Fundamental Contents.
Rodolfo Langhi*

Roberto Nardi**

* Professor Adjunto da Universidade Federal do Mato Grosso do Sul (UFMS). Departamento de Física. Programa de Pós-Graduação em Ensino de Ciências. Grupo de Pesquisa em Ensino de Ciências. Apoio parcial: CAPES. Membro da Rede de Astronomia Observacional (REA). Sócio efetivo da Sociedade Astronômica Brasileira (SAB). E-mail: rodolfo@dfi.ufms.br * * Professor Adjunto, Livre Docente, UNESP. Grupo de Pesquisa em Ensino de Ciências. Departamento de Educação. Programa de PósGraduação em Educação para a Ciência. Faculdade de Ciências. UNESP, Bauru (SP). Apoio CNPq - Conselho Nacional de Desenvolvimento Científico e Tecnológico. E-mail: nardi@fc.unesp.br 


\section{Introdução}

A importância do estudo dos conteúdos disciplinares na formação de professores foi trazida à atenção principalmente com os estudos de Shulman (1987), que os denominou de "paradigma perdido", referindo-se ao fato do enfoque das pesquisas em educação não reconhecerem suficientemente seu papel significativo no desenvolvimento profissional docente. Recentemente, o papel dos demais saberes docentes (além dos saberes disciplinares), na formação profissional de professores, tem sido amplamente discutido por autores tais como Pacheco (1995), Gauthier et al (1998), Porlán e Rivero (1998), Garcia (1999), Pimenta (2000), Tardif (2004) e Borges (2004), dentre outros ${ }^{1}$. No caso específico da Astronomia, os resultados das pesquisas mostram que seus conteúdos não estão sendo trabalhados de maneira significativa, quantitativa e qualitativamente, nem mesmo em cursos de formação inicial de professores. Maluf (2000), Bretones (1999), Ostermann e Moreira (1999), e Barros (1997), por exemplo, comprovam a existência de falhas ligadas diretamente à formação inicial do professor com relação a tópicos de Astronomia.

Seria de se esperar que tais conteúdos pudessem ser abordados, ao menos, nas graduações que levam os estudantes a uma carreira de pesquisa científica, e não especificamente acadêmica, visando saberes docentes disciplinares (TARDIF, 2004). No entanto, segundo a Sociedade Brasileira para o Progresso da Ciência, em geral, somente aqueles jovens físicos que se encaminham para uma pós-graduação, em alguma área diretamente vinculada a problemas de cosmologia, por exemplo, conseguem, pela complementação de seus estudos em centros de pós-graduação, obter uma base adequada de conhecimentos sobre o Universo, pois, a sua graduação não o habilitou a tais conteúdos (SBPC, 2005).

Este exemplo demonstra que a preocupação com a falta de abordagem de saberes disciplinares específicos em Astronomia não é uma característica apenas dos cursos de licenciatura. Contudo, a pesquisa de Bretones (1999) mostrou que há poucas instituições de ensino superior no Brasil que se dedicam ao ensino de alguns destes conteúdos, dependendo da estrutura curricular do curso ministrado. Assim, perguntamos: o que ensinar, afinal, sobre Astronomia nos anos iniciais do ensino fundamental? Buscamos uma resposta ao investigar os saberes disciplinares em Astronomia mais frequentemente apresentados nos resultados de pesquisas sobre ensino de ciências e nos documentos oficiais nacionais de educação, além de apresentar alguns dos conteúdos mais trabalhados durante as trajetórias formativas dos diversos cursos oferecidos no território nacional. A partir desta fundamentação, procuramos elencar um conjunto de conteúdos essenciais em Astronomia para professores dos anos iniciais do ensino fundamental, sem, contudo, transparecer a ideia de uma receita pronta provinda da racionalidade técnica. Por fim, procuramos responder se a formação dos professores deste nível de ensino os habilitaria a abordar, em seu trabalho docente, no mínimo, os saberes disciplinares referentes a estes conteúdos básicos e essenciais de Astronomia. 


\section{Principais conteúdos de Astronomia abordados pela literatura da área}

Investigando os conteúdos programáticos das disciplinas introdutórias específicas que contemplam tópicos de Astronomia nos diversos cursos das instituições de ensino superior do país, Bretones e Compiani (2001) encontraram uma importância maior dada aos temas Sistema Solar, Astronomia de Posição, Sistema Sol-Terra-Lua, e Estrelas, seguidos dos demais temas em ordem decrescente de importância: Galáxias, História e Objeto, Cosmologia, Instrumentos, Céu e Constelações, Tempo e Calendário, Mecânica Celeste, Astrofísica, e por último, o Ensino da Astronomia. Os livros-texto mais usados nas disciplinas introdutórias de Astronomia nestes cursos eram em ordem decrescente de porcentagem: Boczko (1984), Maciel et al (1991), Caniato (1990) e Mourão (1997). ${ }^{2}$

Visando avaliar os professores quanto ao domínio de conteúdos específicos das disciplinas de Física e de Ciências Físicas e Biológicas, o exame escrito de um concurso público do estado de São Paulo, para provimento destes cargos, divulgou um temário de estudo, cujos tópicos incluíam os seguintes conceitos de Astronomia: interações gravitacionais entre objetos na Terra e no Universo; movimentos da Terra, Lua e Sol e fenômenos astronômicos correspondentes; movimento de naves e satélites; o Universo e sua evolução; concepções sobre a Terra e o Universo ao longo da história humana; modelos da origem e evolução do Universo e da Terra; Sistema Solar, tempo e distâncias astronômicas; constituição da Terra; transformações geológicas; condições para a presença de vida, origem da vida; ritmos biológicos e períodos astronômicos (SÃO PAULO, 2003).

Para Tignanelli (1998), os principais conteúdos de Astronomia que deveriam estar presentes no ensino fundamental são os relacionados aos fenômenos cotidianos observáveis e os que dão conta do tipo de universo que habitamos e das leis que os regem: céu e planeta, luz e estrela, nascer e ocaso, dia e noite, órbita, planeta e satélite, dia e noite lunar, fases lunares, manchas solares. Nestes conteúdos estariam implícitos alguns conceitos como movimento relativo, medida do tempo e dimensões, sendo fenômenos, em sua maioria, passíveis de serem observados sem necessidade de um instrumento especial, como um telescópio, por exemplo.

Sintetizando os conteúdos de Astronomia no ensino fundamental, Costa e Gómez (1989) lembram que os mesmos poderiam se limitar a uma simples percepção dos objetos visíveis mais notáveis: estrelas e suas mudanças de posição, incluindo o uso de mapas celestes e planisférios para o estudo mais sistemático de constelações e reconhecimento de planetas; sistema Sol-Terra-Lua e seus movimentos ocasionando fenômenos como o dia, a noite, estações do ano, fases, eclipses; por último, sugere-se noções básicas sobre a constituição do Universo em grande escala, apenas como fator de motivação para as crianças.

Outro exemplo foi uma pesquisa realizada com o intuito de se alterar a disciplina de Física Geral e Experimental do curso de Licenciatura em Ciências 
com Habilitação em Matemática de um instituto de ensino superior, visando estudar a inserção de conteúdos de Astronomia na formação inicial de professores. $\mathrm{Na}$ mudança de conteúdo programático, contemplaram-se os seguintes temas: história da Astronomia, Sistema Solar, estrelas, constelações, galáxias, introdução à Cosmologia, planeta Terra; este último, com caráter interdisciplinar com Geologia, Biologia, Ecologia e Química. Os resultados apontaram para um atendimento das necessidades curriculares e formativas dos futuros professores, que aceitaram a proposta como válida (LATTARI e TREVISAN, 1995).

Conteúdos básicos e essenciais são apontados também por Ostermann e Moreira (1999) como sendo, no mínimo: estações do ano, planetas, e fases da Lua. Os autores mostram ainda que, em razão destes tópicos pouco serem (ou não serem) trabalhados durante a formação inicial e continuada dos professores, alguns acabam reforçando erros conceituais, como as estações do ano decorrentes da variação de distância da Terra em relação ao Sol, por exemplo, conforme constatado em suas pesquisas com professoras dos anos iniciais do ensino fundamental.

Outro exemplo de conteúdos de Astronomia, sugeridos para estudo nos anos iniciais do ensino fundamental, é o fornecido pela Comissão de Ensino da SAB (Sociedade Astronômica Brasileira), como preparatório da Olimpíada Brasileira de Astronomia (SAB, 2009). Embora não se tenha a intenção de ser este evento o determinante sobre o que o professor deva saber a respeito de Astronomia, utilizamos o mesmo como uma das referências para este levantamento de conteúdos ao qual nos propomos.

A proposta curricular para o primeiro segmento do ensino fundamental da educação de jovens e adultos (BRASIL, 1997a), o eixo Terra e Universo, revisado nos PCN, propõe estudos que permitam ao aluno reconhecer a Terra como componente do Sistema Solar e compreender as interações do nosso planeta com o sistema, devendo o professor abordar temas sobre a matéria, energia e vida na Terra. Esta publicação sugere os seguintes fatos, conceitos, procedimentos e atitudes a serem desenvolvidos no eixo temático Terra e Universo: observação direta, busca e organização de informações sobre a duração do dia em diferentes épocas do ano e sobre os horários de nascimento e ocaso do Sol, da Lua e das estrelas ao longo do tempo, reconhecendo a natureza cíclica desses eventos e associando-os a ciclos dos seres vivos e ao calendário; busca e organização de informações sobre cometas, planetas e satélites do Sistema Solar e outros corpos celestes, para elaborar uma concepção de Universo; estabelecimento de relação entre os diferentes períodos iluminados do dia e as estações do ano, mediante observação direta local e interpretação de informações sobre esse fato em diferentes regiões terrestres, para compreensão do modelo heliocêntrico; valorização dos conhecimentos de povos antigos para explicar os fenômenos celestes; valorização do conhecimento historicamente acumulado, considerando o papel de novas tecnologias e o embate de ideias nos principais eventos da história da Astronomia até os dias de hoje; caracterização da constituição da Terra e das condições existentes para a presença de vida. 
De forma similar, os documentos oficiais para a educação nacional, os PCN, reconhecem que a Astronomia é interdisciplinar, pois os assuntos a ela relacionados são tratados em outras disciplinas tais como biologia, física e química. Ao relacionar a hipótese da formação da Terra com outros campos do conhecimento como Geologia, Física e Astronomia, o aluno pode entender que existe um universo muito abrangente de explicações sobre a Terra primitiva (BRASIL, 1999). Assim, embora, de acordo com os PCN, o eixo temático "Terra e Universo" esteja presente somente a partir do terceiro ciclo por motivos circunstanciais, entende-se que "este eixo poderia estar presente nos dois primeiros"(BRASIL, 1998).

Quanto à Astronomia observacional e às constelações, os PCN fornecem três exemplos principais: Cruzeiro do Sul, Órion e Escorpião, afirmando que os alunos podem observar a constelação do Cruzeiro do Sul e seu movimento em relação ao horizonte, em um intervalo de três ou quatro horas durante a noite (BRASIL, 1998). Porém, temos de nos lembrar que a visibilidade do Cruzeiro do Sul depende da latitude em que a cidade se encontra, e do horário da observação. Além disso, esta constelação, assim como muitas outras (incluindo Órion e Escorpião), não são visíveis durante o ano inteiro, havendo períodos do ano em que não conseguimos visualizá-la(s).

Segundo os PCN (BRASIL, 1997), o processo de ensino que inclui a compreensão da natureza do Universo, do espaço, do tempo, da matéria, do ser humano e da vida, tem início na Astronomia, valorizando estudos antigos, por meio dos trabalhos de Copérnico, Kepler e Galileu, quando deslocaram a Terra do centro do Universo, sendo a mecânica do universo melhor entendida depois com o tratamento matemático de Newton. No entanto, esta parece ser uma visão um tanto sistêmica que os PCN apresentam, pois tende a levar o aluno a uma 'revolução copernicana' sem reconhecer antes a importância histórica de uma visão geocêntrica, tais como as grandes navegações, ou que os pilotos de aeronaves ainda aprendem e precisam dos conhecimentos de coordenadas astronômicas num referencial da Terra estática e centralizada. Desta forma, a carga teórica já impõe aos alunos uma visão heliocêntrica, sem antes lhes sugerir uma construção de noções das coordenadas astronômicas e geográficas, partindo da Terra e estendendo para a esfera celeste.

Por isso, o documento reconhece que o conhecimento do modelo heliocêntrico de Sistema Solar, com nove planetas girando ao redor do Sol (na ocasião da produção dos PCN, Plutão ainda era considerado um planeta), tornase complexo, ao colocar-se para os estudantes o conflito entre aquilo que observam, ou seja, o Sol desenhando uma trajetória aparentemente curva no céu, e aquilo que lhes ensinam sobre os movimentos da Terra em torno do Sol. Assim, não seria coerente iniciar o estudo de corpos celestes a partir de um ponto de vista heliocêntrico, ignorando o que os alunos sempre observaram (BRASIL, 1998). De fato, este conflito entre aquilo que observam e aquilo que lhes é ensinado do ponto de vista científico, pode oferecer um certo grau de resistência ao 
aprendizado, uma vez que o geocentrismo parece ser ainda a explicação mais lógica para a concepção do senso comum dos estudantes - fato que deve ser pedagogicamente respeitado pelo professor (OSBORNE e WITTROCK, 1985).

Selecionamos resumidamente, a seguir, alguns conteúdos principais relacionados à Astronomia e o tratamento atribuído a eles, conforme sugeridos pelos PCN: localização, a olho nu, de diferentes constelações e estrelas ao longo do ano e dos planetas; horários de nascimento e ocaso do Sol, da Lua e das estrelas ao longo do tempo; natureza cíclica desses eventos, associando-os a ciclos dos seres vivos e ao calendário; duração do dia em diferentes épocas do ano; diferentes períodos iluminados de um dia e as estações do ano; verificação do movimento das estrelas em relação ao horizonte; posições fixas aparentes das estrelas na esfera celeste; movimentos da Terra, da Lua e demais corpos celestes; compreensão das diferentes distâncias dos corpos celestes vistos no céu; cometas, planetas e satélites do Sistema Solar e outros corpos celestes; modelo de Sistema Solar com tamanhos proporcionais de seus planetas e satélites e respectivas distâncias em escala; conceitos de força da gravidade; fenômeno das marés; estrutura da Terra, estabelecendo relações espaciais e temporais em sua dinâmica e composição; comparação entre as teorias geocêntrica e heliocêntrica; pensamento astronômico da civilização ocidental nos séculos XVI e XVII; estrutura da galáxia e do Universo e os modelos que as explicam; valorização do conhecimento historicamente acumulado, considerando o papel de novas tecnologias e o embate de ideias nos principais eventos da história da Astronomia até os dias de hoje.

A recente produção de artigos sobre Educação em Astronomia na literatura científica nacional entre 1985 e 2008, abordada por Langhi e Nardi (2009), aponta para 95 artigos $^{3}$, analisados principalmente por Iachel (2009) e Marrone Júnior (2007), apresentam os seguintes conteúdos mais abordados: Terra (forma, constituição, campo gravitacional, rotação), órbitas planetárias, Astronomia observacional, instrumentos astronômicos, estrelas, cosmologia e astrofísica.

Como último exemplo de sugestões de conteúdos em Astronomia para os anos iniciais do ensino fundamental, apresentamos parte dos resultados da pesquisa de Langhi (2004), que aborda temas a serem estudados em um possível programa de formação continuada ou na preparação de materiais didáticos:

Observação do Céu: noções de localização no espaço, movimento aparente dos astros, diferenças das estrelas, constelações, cartas celestes, constelações da época, condições para observações astronômicas.

Sistemas de medidas: tempo universal, magnitude aparente, tamanho aparente, esfera celeste, localização de um astro no céu, medição dos astros, medidas de distâncias aparentes, medidas de distâncias reais, unidade astronômica, ano-luz.

Instrumentos astronômicos: tipos de telescópios, ampliação de um telescópio, ampliação máxima de um instrumento, acessórios de instrumentos astronômicos, luminosidade de um telescópio, mapas lunares, mapas estelares, sugestões para uma observação de qualidade, construção artesanal de telescópios e outros instrumentos astronômicos. 
Sistema Solar: observação da Lua e do Sol, observação dos planetas, Júpiter, Saturno, Marte, Vênus, Mercúrio, Urano, Netuno, Plutão, asteróides, cometas, meteoros.

Obejtos de Céu Profundo: estrelas, estrelas duplas, estrelas variáveis, aglomerados estelares, aglomerados abertos, aglomeradas globulares, nebulosas, galáxias.

Fenômenos celestes: satélites artificiais, chuvas de meteoros, ocultações, trânsitos, novas e supernovas, eclipses, eclipses solares, eclipses lunares, dia/noite, estações do ano, fases da Lua.

Tecnologia espacial brasileira: breve histórico do programa espacial, o astronauta brasileiro, satélites nacionais, investimentos em tecnologia espacial no Brasil, funcionamento de foguetes, monitoramento do meio ambiente, lixo espacial.

Apoio ao professor: sugestões bibliográficas, sugestões de páginas na internet, endereços dos principais observatórios e planetários do país, tabelas, mapas, pôsteres, disponibilização de materiais, instrumentos e experimentos, respostas às perguntas mais frequentes sobre Astronomia.

Propostas de projetos: projetos observacionais e de coleta de dados para professores e alunos, construção de telescópios artesanais, parcerias com amadores, observatórios e planetários, utilização de verba pública de secretarias municipais e estaduais de educação para a compra (ou construção) de telescópios e instrumentos didáticos de Astronomia, e a busca de parcerias com universidades pelo professor de educação básica.

Diante desta pluralidade de conteúdos, perguntamos: quem, afinal, define e seleciona os conteúdos de Astronomia a serem ensinados? Ampliando a questão (e isso vale não apenas para a Astronomia), quem é responsável por estabelecer determinados temas de ensino nas escolas? Tal problemática parece ser histórica e tradicional, pois segundo a proposta curricular para o primeiro segmento do ensino fundamental da educação de jovens e adultos (BRASIL, 1997a), há mais de trinta anos, ocorre uma distribuição tradicional dos conteúdos, caracterizada pela seguinte seleção e organização: ar, água e solo, na $5^{\text {a }}$ série; seres vivos, na $6^{a}$ série; corpo humano, na $7^{\mathrm{a}}$ série; Física e Química, na $8^{\mathrm{a}}$ série. Ecologia é vista na $5^{\mathrm{a}}$ ou $6^{\mathrm{a}}$ série. A Astronomia possui lugar variável, aparecendo geralmente na $5^{\mathrm{a}}$ e na $6^{\mathrm{a}}$ séries, junto com estudos dos seres vivos.

Este documento ainda salienta que esta abordagem foi consolidada pelos livros didáticos, e encontra-se, atualmente, bem arraigada entre os professores de Ciências, os quais vêm repetindo a mesma fórmula, com pequenas variações - como a inserção, na $5^{\mathrm{a}}$ série, de temas mais atuais, ligados às questões ambientais ou à saúde (BRASIL, 1997a). Além disso, Pietrocola (2005) declara a influência que os exames vestibulares exercem para a determinação dos conteúdos a serem editados nos manuais didáticos e, consequentemente, nas aulas. As Orientações Curriculares para o ensino médio enfatizam, igualmente, que os conteúdos e a metodologia de ensino, praticados na educação básica, são voltados principalmente para os exames vestibulares, propagando-se a ideia de que as melhores escolas são aquelas que mais aprovam nestas provas (BRASIL, 2006). 


\section{Astronomia Essencial}

Diferentemente destas imposições autoritárias de conteúdos disciplinares, tentamos encontrar um conjunto de conteúdos essenciais de Astronomia a serem ensinados nos anos iniciais do ensino fundamental, conforme as propostas, sugestões e resultados de pesquisas das fontes comentadas no item anterior. Apresentamos, assim, na tabela 01, uma síntese das fontes até agora consultadas e as temáticas por elas abordadas. Consideramos tais fontes como uma amostragem, uma vez que não foi objetivo de nosso trabalho esgotar a consulta a todas as produções nacionais que contemplam referências a tópicos de Astronomia para este nível de ensino. Todavia não é nossa intenção transparecer a ideia da imposição em se determinar conteúdos definitivos, provinda de uma racionalidade técnica autoritária (GAUTHIER et al, 1998).

Tabela 1: Síntese das fontes consultadas que abordam o ensino de conteúdos de Astronomia

\begin{tabular}{|c|c|c|c|c|c|c|c|c|c|c|c|c|}
\hline Conteúdo & 01 & 02 & 03 & 04 & 05 & 06 & 07 & 08 & 09 & 10 & 11 & 12 \\
\hline Forma da Terra & $X$ & $x$ & $X$ & $x$ & $x$ & $x$ & $x$ & $x$ & $x$ & & $X$ & $x$ \\
\hline Fases da Lua & $X$ & $X$ & $X$ & $X$ & $X$ & $X$ & $X$ & $X$ & $X$ & $X$ & & $X$ \\
\hline Estações do ano & $\mathrm{X}$ & $X$ & $X$ & $X$ & $X$ & $X$ & $X$ & $X$ & $X$ & $X$ & & $X$ \\
\hline Campo gravitacional & $\mathrm{X}$ & $X$ & $\mathrm{X}$ & $\mathrm{X}$ & $X$ & $X$ & $\mathrm{X}$ & $X$ & $X$ & & & $\mathrm{X}$ \\
\hline Dia e noite & $X$ & $X$ & $X$ & $X$ & $X$ & $X$ & $X$ & $X$ & & $X$ & & $X$ \\
\hline Órbita terrestre & $X$ & $X$ & $\mathrm{X}$ & $X$ & $X$ & $X$ & $\mathrm{X}$ & $X$ & & $X$ & & $X$ \\
\hline Astronomia observacional & $\mathrm{X}$ & $X$ & & $X$ & $X$ & $X$ & $\mathrm{X}$ & $X$ & & $X$ & $X$ & $X$ \\
\hline Corpos do Sistema Solar & $\mathrm{X}$ & $X$ & $\mathrm{X}$ & $X$ & & $X$ & & & $X$ & & $\mathrm{X}$ & \\
\hline Estrutura do Universo: estrelas,galáxias... & $X$ & $X$ & & $X$ & $X$ & & & $X$ & & $X$ & $X$ & $X$ \\
\hline História da Astronomia & $X$ & $\mathrm{X}$ & $\mathrm{X}$ & & & & $X$ & & & & $\mathrm{X}$ & \\
\hline Tempo e Calendário & $\mathrm{X}$ & $\mathrm{X}$ & $\mathrm{X}$ & $X$ & $X$ & & & & & & & \\
\hline Cosmologia & $X$ & $X$ & $\mathrm{X}$ & & & & & & & & $\mathrm{X}$ & $\mathrm{X}$ \\
\hline Vida (abordagem astronômica) & & $X$ & $X$ & & & $X$ & & & $X$ & & & \\
\hline Instrumentos astronômicos & $X$ & $X$ & & $X$ & & & & & & & & \\
\hline Astron. de posição e mecânica celeste & $X$ & & & & & & & & & & & \\
\hline Astrofísica & $X$ & & & & & & & & & & & $X$ \\
\hline
\end{tabular}

\footnotetext{
Legenda:

1) Análise dos cursos das instituições de formação inicial, (BRETONES e COMPIANI, 2001)

2) Conteúdos de estudo para a Olimpíada Brasileira de Astronomia e Astronáutica (SAB, 2009)

3) Temário do concurso para professor de Ciências Físicas e Biológicas (SÃO PAULO, 2003)

4) Trabalho de mestrado de Langhi (2004)

5) Resultados de pesquisa de Tignanelli (1998)

6) Proposta curricular para a educação de jovens e adultos (BRASIL, 1997a)

7) Parâmetros Curriculares Nacionais (BRASIL, 1997 e 1998)

8) Resultados de pesquisas sobre concepções alternativas (BARRABIN, 1995; TRUMPER, 2001)

9) Resultados de pesquisa de Ostermann e Moreira (1999)

10) Resultados de pesquisa de Costa e Gómez (1989)

11) Resultados de pesquisa de Lattari e Trevisan (1995)

12) Análise de artigos sobre ensino de Astronomia, segundo lachel (2009) e Marrone Júnior (2007).
}

Analisando as fontes consideradas até agora neste texto (cujos conteúdos abordados estão assinalados na tabela 01), e baseando-nos nas propostas oficiais para a educação brasileira, bem como nos resultados das pesquisas sobre Educação em Astronomia, entendemos que os conceitos referentes à forma da Terra, campo gravitacional, dia e noite, fases da lua, órbita terrestre, estacões do ano e Astronomia observacional constituem-se em um conjunto de sete conteúdos básicos e fundamentais para que o professor dos anos iniciais do ensino fundamental 
atue como um mediador na preparação de um alicerce sólido a fim de que o aluno construa posteriores conhecimentos, de modo a compreender estes e outros fenômenos astronômicos cotidianos. Um reforço em favor da existência deste elenco de conteúdos básicos é o fato de que são estes os que também mais aparecem nas pesquisas sobre concepções alternativas em Astronomia (BARRABÍN, 1995; TRUMPER, 2001; PEÑA e QUILEZ, 2001; SEBASTIÁ, 1995).

O sétimo conteúdo, a Astronomia observacional, nos chama a atenção no sentido de sua importância motivacional, histórica e cultural, e pela ampla carência nacional com relação à falta de um fabricante brasileiro de telescópios, embora se sugira a utilização destes instrumentos no ensino. Além disso, há poucas dezenas de construtores artesanais de telescópios no Brasil, produzindo-os a custos inferiores aos praticados no mercado das importações e com qualidade comparável ou superior aos instrumentos de produção em massa a partir de outros países. ${ }^{4}$

Assim, à base de trabalhos publicados na área da Educação em Astronomia e do campo de conhecimentos constituídos até o momento, poderíamos atribuir a este conjunto de sete conceitos básicos, uma importância fundamental, sobre a qual poderia se apoiar a estruturação de programas de formação docente planejados para os anos iniciais do ensino fundamental, visando o direito, que o jovem, em idade escolar, possui, de conhecer, no mínimo, estes sete conceitos nucleares. A este conjunto, portanto, chamaríamos de Astronomia essencial para o ensino fundamental, que se localizariam no âmbito da alfabetização astronômica, podendo permear os saberes disciplinares - e os saberes didáticos do conteúdo a ser ensinado - de todo o professor que pretende atuar neste nível de ensino, dentro de nosso contexto nacional.

Além disso, é plausível que o professor respeite o nível cognitivo dos alunos, bem como seus aspectos metodológicos e didáticos, a fim de reconhecer que, nos anos iniciais do ensino fundamental, o ensino de alguns destes conteúdos da Astronomia essencial deve se dar sob um referencial topocêntrico e geocêntrico, conforme já comentado anteriormente (OSBORNE e WITTROCK, 1985).

Portanto, ao evidenciar este conjunto mínimo de conteúdos básicos que o professor dos anos iniciais do ensino fundamental precisaria conhecer, sob o nosso ponto de vista, intencionamos apresentar uma visão geral dos resultados que as pesquisas em ensino de ciências têm demonstrado como os tópicos principais mais frequentes em ensino de Astronomia, e não como uma estruturação curricular rígida e baseada na racionalidade técnica. Nem é nossa intenção promover qualquer tipo de "receita pronta" no sentido de impor o ensino de uma lista de conteúdos fragmentados. 


\section{Investigando a Astronomia essencial em uma amostra}

A partir da identificação de um conjunto de conteúdos fundamentais em Astronomia ("currículo mínimo"), que denominamos de Astronomia essencial, conforme apontado pelos resultados do levantamento acima, retomamos à problemática inicial: estaria a formação de professores dos anos iniciais do ensino fundamental levando em conta suas necessidades formativas quanto aos seus saberes disciplinares relacionados à Astronomia essencial?

Os resultados que apresentaremos, a seguir, fazem parte de uma investigação mais ampla sobre a formação docente e foram constituídos por uma amostra de 15 professores dos anos iniciais do ensino fundamental durante um curso noturno de curta duração em Astronomia, realizado no Núcleo de Aperfeiçoamento de Professores da Educação Municipal (NAPEM), de Bauru, Estado de São Paulo, no primeiro semestre de 2008. ${ }^{5}$

Os dados pessoais desta amostra caracterizam-na com uma média de idade de 39 anos, variando entre 62 e 24 anos. A média do tempo de experiência é de 14 anos, com um máximo de 30 anos e um mínimo de três anos de experiência. Havia, no grupo, nove professores que trabalhavam nos anos iniciais do ensino fundamental e dois que exerciam outras funções pedagógicas, não lecionando no período do curso. Quatro professores trabalhavam também na educação infantil e um no ensino superior. Quanto à formação inicial, dez respostas da amostra (67\%) indicam o curso de Pedagogia; cinco com cursos de menor probabilidade de trabalho com conteúdos de Astronomia: três de História (20\%) e duas de Psicologia (13\%); e quatro professores com cursos de maior probabilidade de trabalho com conteúdos de Astronomia: três de Ciências Biológicas $(20 \%)$ e uma de Geografia (7\%), salientando que há professores participantes de dois cursos. Quanto à inclusão digital desta amostra, os resultados indicam que quase todos (dez respondentes) possuem acesso facilitado à internet, sem dificuldades de utilização, enquanto quatro respostas indicam um pequeno grau de problemas com seu uso, e uma com acesso limitado.

Dos professores da amostra, apenas um comenta que revisou superficialmente conceitos básicos de Astronomia na graduação (curso de Geografia), ao passo que os demais negam ter estudado conteúdos desta natureza. Quanto a cursos adicionais de Astronomia, nenhum deles havia participado.

Conforme aponta Garcia (1999), é importante, para o formador, conhecer antecipadamente as reais necessidades formativas dos professores participantes de um curso de formação continuada, para atender às suas expectativas e facilitar a mobilização de quaisquer mudanças no ato de ensinar. Em nosso caso, a investigação acerca das concepções em Astronomia desta amostra constituiu-se em apenas uma parte deste levantamento antecipado das necessidades docentes, visando reestruturações no conteúdo programático do curso, a fim de procurar atender suas expectativas (LANGHI e NARDI, 2008a). Para tanto, utilizamos o instrumento questionário auto-aplicado, segundo as classificações e defi- 
nições metodológicas de Gil (1991 e 1996). Esta técnica é a mais frequentemente utilizada, conforme Garcia (1999), dentre as estratégias para o diagnóstico de necessidades e preocupações dos professores. No entanto, reconhecemos que este é apenas um passo prévio de uma análise mais profunda, pois este serve de ponto de partida para se iniciar uma seleção negociada com os professores, com base no consenso e diálogo.

Deste modo, apresentamos ao grupo, mediante projeção simultânea em anteparo, algumas questões conceituais sobre Astronomia, as quais foram respondidas simultânea e individualmente, por escrito, sem identificação (as questões estão apresentadas no apêndice). Partindo para uma análise predominantemente conceitual em Astronomia, estas questões envolveram os fenômenos básicos sobre o tema, cujos saberes disciplinares deveriam estar bem constituídos durante a trajetória de formação inicial (graduação) e afirmados mediante o trabalho docente no âmbito dos saberes experienciais, segundo a concepção da pesquisa sobre saberes docentes (TARDIF, 2004; PIMENTA, 2000; BORGES, 2004). Tal conjunto mínimo de saberes disciplinares em Astronomia, apresentado no questionário, corresponde justamente à Astronomia essencial, sugerida anteriormente como um currículo fundamental a ser trabalhado nos anos iniciais no ensino fundamental, conforme apontou a literatura acima investigada.

Ressaltamos, porém, que o levantamento das concepções alternativas em Astronomia desta amostra teve como principal finalidade qualitativa procurar entender algumas das necessidades conceituais deste grupo de professores, a fim de atendê-las no decorrer do curso, pois reconhecemos que o movimento das concepções alternativas já teve a sua importante atuação em anos anteriores (CACHAPUZ et al, 2005). Por outro lado, os resultados, aqui apresentados, visam esclarecer principalmente o questionamento levantado inicialmente, a saber, até que ponto os professores foram capacitados a construir saberes disciplinares referentes a estes conteúdos básicos e essenciais de Astronomia, durante sua formação docente, seja inicial ou continuada.

Com relação à primeira questão conceitual (ver apêndice) aplicada à amostra, sua abrangência atua tanto na forma da Terra quanto no campo gravitacional da mesma. Pesquisas anteriores já foram efetuadas acerca de concepções alternativas neste tópico, tais como as de: Nussbaum (1979), Nussbaum e Novak (1976), Nardi e Carvalho (1996), Baxter (1989), Zeilik (1998), Jones, Lynch, Reesinch e Schoon, estudados por Barrabín (1995), Vosniadou, Lightman e Sadler, analisados por Trumper (2001). Algumas apontam para, pelo menos, cinco noções principais acerca desta temática, conforme resume a figura abaixo. 
Figura 1: Noç̃oes sobre a Terra e gravidade, conforme Nussbaum e Novak (1979)

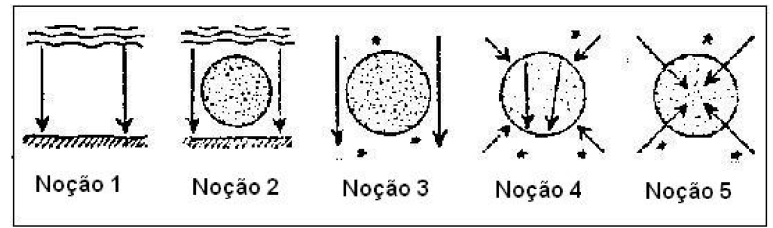

As respostas dos 15 professores da amostra a esta questão se assemelharam a estas noções, de modo que foram classificadas igualmente, obtendo as seguintes informações: cinco deles concebem uma Terra semelhante à da noção 3 , enquanto seis correspondem à noção 4, e quatro professores concebem-na como um corpo mais próximo à concepção cientificamente aceita, a noção 5 . A figura, a seguir, registra algumas destas concepções encontradas na amostra.

Figura 2: Exemplos de concepções sobre campo gravitacional terrestre encontradas na amostra

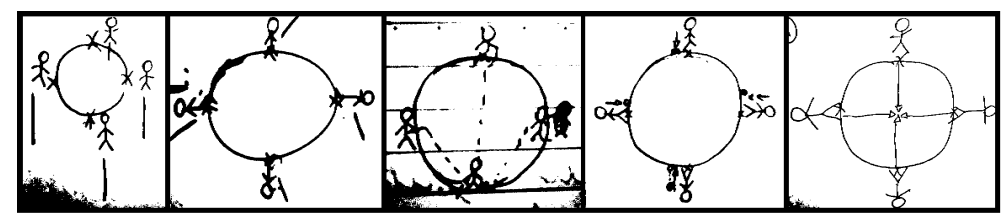

Quanto às concepções a respeito do fenômeno do dia e da noite, diversas pesquisas apontam para algumas classificações de noções básicas: Vosniadou e Brewer (1992), Camino (1995) e Trumper (2001), além de Lightman, Sadler e Brewer, estudados pelo próprio Trumper (2001), e de Klein, analisado por Barrabín (1995). Porém, tomamos como base a classificação de Baxter (1989) em seis diferentes noções, as quais numeramos de 1 a 6 , na figura abaixo.

Figura 3: Noções de estudantes sobre o dia e a noite (BAXTER, 1989)

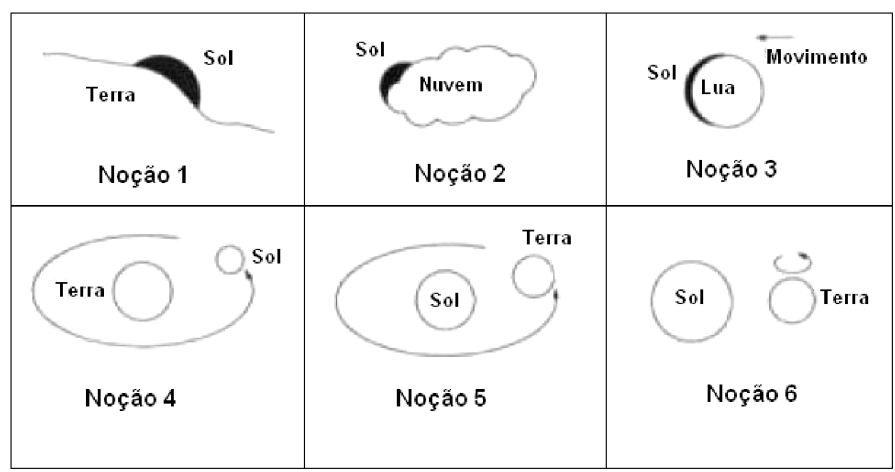


Em nossa amostra, encontramos 10 professores cujas respostas adequaram-se ao modelo da noção 6; um professor que expressou a necessidade de consultar um livro didático para se sentir apto a responder a esta questão; e um que associou um cometa girando em torno do Sol como o motivo do fenômeno do dia e da noite. Outros três professores não apresentaram respostas compatíveis ao modelo cientificamente aceito, mas suas frases associaram-se a termos do tipo slogans e chavões, característicos de livros didáticos e muito comuns nos discursos de professores, segundo Bisch (1998).

As concepções sobre fases da Lua também já foram alvo de levantamentos no movimento das pré-concepções, tais como em Brewer, Lightman e Sadler, estudados por Trumper (2001); Baxter (1989); Camino (1995); Peña e Quilez (2001); Stahly (1999); Trumper (2001); e Zeilik (1998). Novamente, apoiamo-nos em Baxter (1989) para sintetizar as noções deste fenômeno, conforme a Figura 4.

Nossa amostra apresentou apenas um professor cujas explicações concordaram com a noção 5 , a concepção cientificamente aceita. Sete respostas indicaram pendências para a noção de número 4, porém as frases incompletas e carregadas de slogans semelhantes aos dos livros didáticos (com o uso de termos tais como: "depende do movimento", "por causa da posição") não permitiram uma classificação bem definida, mas certamente não remetem à noção 5. Apenas uma resposta deixou claro que as fases da Lua correspondiam à sombra que a Terra lança sobre ela (noção 4). Três reconheceram a necessidade de consulta a um livro didático para fornecer a resposta, e quatro afirmaram desconhecer a explicação para tal fenômeno, totalizando sete abstenções de respostas.

Figura 4: Noç̃ões de estudantes sobre as fases da Lua (BAXTER, 1989)

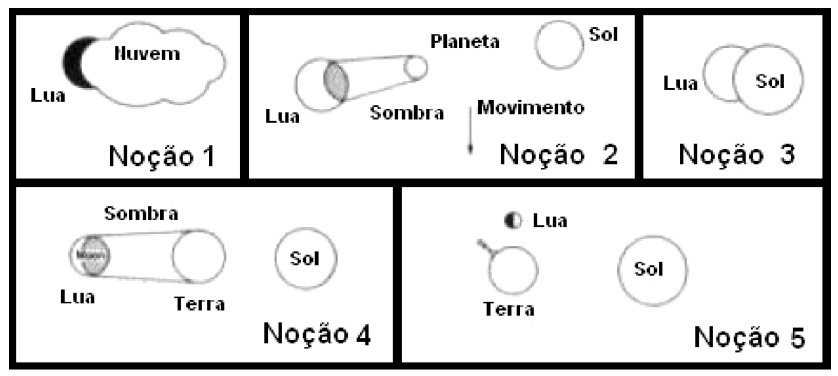

Concepções sobre a órbita terrestre, que tem sua excentricidade exageradamente representada em vários materiais didáticos (LANGHI e NARDI, 2007), também foram amplamente estudadas por autores tais como Barrabín (1995); Trumper (2001); e Canalle (2003), além de Giordan, Vecchi, Kapterer e Dubois, estudados por Barrabín (1995), e Durant, Acker e Pecker, analisados por Trumper (2001). Nesta questão não-aberta, o professor da amostragem optava por uma das três alternativas sobre a órbita terrestre: uma de excentricidade bem 
exagerada, outra de excentricidade quase nula (praticamente uma circunferência), e uma de excentricidade intermediária. Apenas dois sujeitos da amostra optaram por uma órbita praticamente circular, o que representa acertadamente o conceito científico, cujo valor da excentricidade da órbita elíptica terrestre é de 0,02 (quanto mais próximo de zero, mais de uma circunferência a figura se aproxima). Outros dois assinalaram a figura intermediária, enquanto 11 optaram pela órbita extremamente elíptica.

A questão da órbita terrestre está diretamente relacionada a algumas concepções alternativas sobre estações do ano (CANALLE, 2003; LANGHI e NARDI, 2007). Outros estudos relacionados com as concepções a respeito deste fenômeno podem ser encontrados em: Camino (1995); Barrabín (1995); Baxter (1989); Trumper (2001); Ostermann e Moreira (1999); além de Schoon, estudado por Barrabín (1995), Lightman e Sadler, analisados por Trumper (2001).

$\mathrm{Na}$ presente amostra, foram identificados três professores que apontaram como causa das estações do ano, a variação de distância da Terra em relação ao Sol. Um respondeu que precisa do livro didático para uma maior segurança em responder, e outro relacionou as estações apenas com a mudança do clima. Seis respostas apontaram para explicações diferentes da concepção científica, pois suas ideias incompletas remetem a termos tais como "inclinação do eixo", "translação", e "rotação", sem, contudo, fornecerem um modelo completo, não articulando estes termos com o modelo científico sobre a real causa das estações do ano.

Quanto à Astronomia observacional (questões 6 e 7), o relato de ter observado o céu por um telescópio apenas uma vez ocorreu para dois professores, e mais de uma vez para três deles. Porém, dez (67\%) professores jamais tiveram a oportunidade de utilizar um instrumento desta natureza e nem visitar um observatório ou planetário. Apenas uma resposta indicava que um professor levou seus alunos a um planetário, e cinco indicavam visitas pessoais a planetários, sem compromissos com a escola. Um professor relata uma visita pessoal (sem alunos) ao observatório da região (Observatório Didático Astronômico da UNESP de Bauru) durante um evento público em que ocorreu um eclipse lunar. Quanto à identificação de constelações, três professores relataram saber identificar as "Três Marias" (mas não a inteira constelação de Órion), oito a constelação do Cruzeiro do Sul, e dois a constelação do Escorpião. Algumas das poucas pesquisas que abordam a Astronomia observacional no ensino são: Vosniadou (1987, apud TRUMPER, 2001); Scalvi et al (2006); Alves e Zanetic (2008).

Portanto, como mostram nossos resultados e os de pesquisas anteriores sobre concepções alternativas em Astronomia ${ }^{6}$, muitos professores possuem tais concepções, até mesmo sobre conteúdos de Astronomia essencial. Este fato parece indicar que nossa amostra talvez não esteja tão distante dos outros docentes pesquisados, no Brasil e no mundo, com relação às suas necessidades formativas sobre saberes disciplinares no que tange a conceitos básicos de Astronomia fundamental. 


\section{Considerações Finais}

Caso o professor não domine os saberes disciplinares em Astronomia essencial, devido principalmente a lacunas durante sua formação inicial, é preocupante imaginá-lo trabalhando em sala de aula com saberes disciplinares construídos a partir de outras fontes de consulta (nem sempre seguras), tais como a mídia sensacionalista, livros didáticos contendo erros conceituais (LANGHI, 2005), ou sua própria experiência advinda dos anos do ensino fundamental, enquanto aluno (LANGHI, 2004).

Ao demonstrarmos que, mesmo nestes conteúdos essenciais, há a persistência de concepções alternativas por parte dos docentes, expõe-se a situação de despreparo do professor, que pode proporcionar, durante o processo de ensino e aprendizagem, o surgimento ou o reforço de concepções alternativas sobre fenômenos astronômicos, acarretando em sérios erros conceituais em Astronomia durante as aulas que deveriam contemplar conteúdos de Ciências (LANGHI e NARDI, 2008).

De fato, a maioria da literatura sobre concepções alternativas, na área de Educação em Astronomia, tem confirmado, conforme a revisão bibliográfica de Driver (1989), que há conceitos básicos da Astronomia essencial não completamente compreendidos e que podem oferecer resistências a "mudanças conceituais" ou ao aprendizado de conceitos mais complexos, se não forem adequadamente tratados antecipadamente.

Assim, cursos de curta duração em Astronomia (normalmente nomeados de "formação continuada") procuram minimizar esta problemática, principalmente sob uma abordagem expositiva de conteúdos, sem levar em conta, muitas vezes, a constatação da efetivação da mudança da prática do professor em sala de aula durante momentos posteriores ao curso, a fim de verificar a sua atuação com relação ao ensino adequado de conteúdos tão fundamentais quanto à Astronomia essencial (LANGHI, 2009). De fato, resultados de pesquisas, tais como as apresentadas por Sampaio (1998), Pimenta (2000), Mizukami et al (2002) e Garcia (1999), apontam que muitos cursos denominados de formação continuada, não passam de meras atualizações de conteúdo, não alterando significativamente a prática docente. Ademais, há outras abordagens de formação docente que precisam ser levadas em conta, além da conteudista, tais como a humanista, ativista, reflexista e tecnicista (LANGHI, 2009).

Portanto, os dados mostram a necessidade de melhoria na qualificação profissional docente, não apenas em relação aos seus saberes disciplinares (conteúdos), mas também em metodologias de ensino e demais saberes docentes. Tal qualificação formativa deveria estar embasada, não no senso comum de seus executores e suas instituições formadoras responsáveis, mas nos resultados das pesquisas sobre Educação em Astronomia, a fim de contemplar, no mínimo, os conteúdos fundamentais sobre este tema e suas metodologias de ensino. Por isso, reforçamos a necessidade de uma efetivação nacional de trabalhos formativos 
docentes segundo modelos de formação contextualizados e norteados pelos resultados das pesquisas da área de Educação em Astronomia (a qual, aliás, compõe-se ainda em um campo fértil de trabalho), visando contribuir significativamente para a mudança da prática docente, a favor de uma Educação em Astronomia que contemple os conteúdos mínimos e fundamentais, sem erros conceituais, os quais denominamos, neste texto, de Astronomia essencial.

\section{Apêndice}

1) A circunferência abaixo representa o planeta Terra. Coloque as 4 pessoas sobre sua superfície nas posições marcadas com um " $X$ ". Agora, desenhe uma linha que represente a queda de um objeto que é largado por cada pessoa.

2) Qual das figuras abaixo representa melhor o caminho (órbita) que a Terra faz ao girar em torno do Sol?

3) Como você explicaria o funcionamento das estações do ano? Como elas ocorrem? Para responder, faça um desenho, esquema, ou texto.

4) Como você explicaria as fases da Lua? Como elas ocorrem?

5) Como você explicaria a ocorrência do DIA e da NOITE?

6) Você já realizou alguma observação por telescópio? Relate também se você já visitou um planetário ou observatório. Em caso positivo, queira nos informar quando, onde e o que observou. Se desejar, por favor, relate também suas impressões sobre isto.

7) Escreva os nomes de algumas constelações que você sabe, com certeza, identificar no céu. 


\section{NOTAS}

1 Para uma consideração mais detalhada a respeito dos saberes docentes na formação de professores e suas possíveis aproximações, ver Langhi (2009).

2 Para uma lista de livros e outras bibliografias que podem ser consultadas pelo professor como fonte de informação, veja: http://sites.google.com/site/proflanghi

3 Uma lista desta produção, incluindo links de acesso direto para cada artigo on-line, está disponível na homepage do autor, em http://sites.google.com/site/proflanghi/artigos

4 Por exemplo, em Bauru (SP), um projeto de Extensão Universitária, coordenado pela Profa. Dra. Rosa Maria Fernandes Scalvi, financiado pela Fundação para o Desenvolvimento da UNESP (Fundunesp), envolve, desde 2003, a construção artesanal de telescópios com ações de popularização e ensino, bem como de interdisciplinaridade com o curso de Licenciatura em Física, a partir da colaboração de um destes poucos construtores brasileiros de telescópios. As ações culminaram com a implantação do Observatório Didático Astronômico "Lionel José Andriatto" (o nome é em homenagem a este construtor bauruense), em 2006, nas dependências do IPMet (Instituto de Pesquisas Meteorológicas da UNESP), por meio de um projeto aprovado pelo Conselho Nacional de Desenvolvimento Científico e Tecnológico (CNPq). Atualmente, ampliações estão em andamento (http://unesp.br/astronomia).

5 A pesquisa estudou múltiplos elementos formativos, sendo um deles as concepções levantadas antes da aplicação do curso em questão, conforme apresentadas neste texto (LANGHI, 2009).

6 Visando facilitar a procura pelos artigos de interesse, reproduzimos uma lista de 160 referências a artigos internacionais sobre ensino da Astronomia (alguns deles citados neste artigo), denominada de Searchable Annotated Bibliography of Education Research in Astronomy (BRISSENDEN, BRUNING, e SLATER, 2001), além de disponibilizar a relação dos títulos e resumos de teses e dissertações nacionais sobre Educação em Astronomia, produzidas desde 1973, na bomepage do autor: http://sites.google.com/site/proflanghi/onde

\section{REFERÊNCIAS BIBLIOGRÁFICAS}

ALVES, M. T. S. \& ZANETIC, J. O ensino não formal da Astronomia: um estudo preliminar de suas ações e implicações. In: Encontro de Pesquisa em Ensino de Física, 11, Curitiba, 2008. Atas... Curitiba: UFPR, 2008.

BARRABÍN, J. M. ¿Por qué hay veranos e inviernos? Representaciones de estudiantes (12-18) y de futuros maestros sobre algunos aspectos del modelo Sol-Tierra. Enseñanza de las Ciencias, v. 13, n. 2, p. 227-236, 1995.

BARROS, S. G. La Astronomía en textos escolares de educación primaria. Enseñanza de las Ciencias, v. 15, n. 2, p. 225-232, 1997.

BAXTER, J. Children's understanding of familiar astronomical events. International Journal of Science Education, v. 11, special issue, p. 502-513, 1989.

BISCH, S. M. Astronomia no ensino fundamental: natureza e conteúdo do conbecimento de estudantes e professores. 1998. 301 f. Tese (Doutorado em Ensino de Ciências), IF/USP, São Paulo, 1998.

BOCZKO, R. Conceitos de Astronomia. São Paulo: Blucher, 1984.

BORGES, C. O professor da educação básica e seus saberes profissionais. Araraquara: JM, 2004.

BRASIL. Secretaria de Educação Média e Tecnologia. Parâmetros Curriculares Nacionais: ciências naturais. Brasília: MEC/SEMTEC, 1997.

BRASIL. Educação de Jovens e Adultos: Proposta curricular para o primeiro segmento do ensino fundamental. Ministério de Educação e do Desporto. Secretaria de Educação Fundamental. Brasília: MEC, 1997a.

BRASIL. Secretaria de Educação Média e Tecnologia. Parâmetros Curriculares Nacionais: terceiro e quarto ciclos do ensino fundamental - ciências naturais. Brasília: MEC/SEMTEC, 1998. 
BRASIL. Secretaria de Educação Média e Tecnologia. Parâmetros Curriculares Nacionais: Ciências da natureza, matemática e suas tecnologias. Brasília: MEC/SEMTEC, 1999.

BRASIL. Secretaria de Educação Básica. Orientações curriculares para o ensino médio: ciências da natureza, matemática e suas tecnologias. Vol. 2. Brasília: Ministério da Educação, 2006.

BRETONES, P. S. Disciplinas introdutórias e Astronomia nos cursos superiores do Brasil. Dissertação de Mestrado. Campinas, Instituto de Geociências, UNICAMP, 1999.

BRETONES, P. S. \& COMPIANI, M. Disciplinas introdutórias de Astronomia nos cursos superiores do Brasil. Boletim da Sociedade Astronômica Brasileira, v. 20, n. 3, p. 61-82, 2001.

BRISSENDEN, G.; BRUNING, D. H. \& SLATER, T. F. SABER: A Searchable Annotated Bibliography of Education Research in Astronomy. Bulletin of the American Astronomical Society, 33(4), p. 660, EUA, 2001.

CACHAPUZ, A. et al (org.). A necessária renovação do ensino das ciências. São Paulo: Cortez, 2005.

CAMINO, N. Ideas previas y cambio conceptual en Astronomía. Un estudio con maestros de primaria sobre el día y la noche, las estaciones y las fases de la luna. Enseñanza de las Ciencias, v. 13, n. 1, p. 81-96, 1995.

CANALLE, J. B. G. O problema do ensino da órbita da Terra. Física na Escola, São Paulo, v. 4, n. 2, p. 12-16, out. 2003.

CANIATO, R. O céu. São Paulo: Ática, 1990.

COSTA, A. A.; GOMÉZ, V. R. La Astronomía en la enseñanza obligatoria. Enseñanza de las Ciencias, v. 7, n. 2, p. 201-205, 1989.

DRIVER, R. Student's conceptions and the learning of science. International Journal of Science Education, v. 11, n. 5, p. 481-490, 1989.

GARCIA, C. M. Formação de professores: para uma mudança educativa. Portugal: Porto Editora, 1999.

GAUTHIER, C. et al. Por uma teoria da pedagogia: pesquisas contemporâneas sobre o saber docente. Ijuí/BRA: Editora UNIJUÍ, 1998.

GIL, A. C. Técnicas de pesquisa em economia. $2^{\circ}$ ed. São Paulo: Atlas, 1991.

GIL, A. C. Como elaborar projetos de pesquisa. $3^{a}$ ed. São Paulo: Atlas, 1996.

IACHEL, G. Um estudo exploratório sobre o ensino de Astronomia na formação continuada de professores. 2009. 229 f. Dissertação (Mestrado em Educação para a Ciência). Faculdade de Ciências, UNESP, Bauru, 2009.

LANGHI, R. Um estudo exploratório para a inserção da Astronomia na formação de professores dos anos iniciais do Ensino Fundamental. Dissertação (Mestrado em Educação para a Ciência). Faculdade de Ciências, UNESP, Bauru, 2004.

LANGHI, R. Ideias de senso comum em Astronomia. In: Observatórios Virtuais. São Paulo: IAG/USP, v. CDROM, p. 1-9, 2005.

LANGHI, R. Astronomia nos anos iniciais do ensino fundamental: repensando a formação de professores. Tese (Doutorado em Educação para a Ciência). Faculdade de Ciências, UNESP, Bauru, 2009. Disponível em: <http://sites.google.com/site/proflanghi>. Acesso em: 28 dez. 2009.

LANGHI, R. \& NARDI, R. Ensino de Astronomia: erros conceituais mais comuns presentes em livros didáticos de ciências. Caderno Brasileiro de Ensino de Física, v. 24, n.1, p. 87-111, abr. 2007. Disponível em: <http://www.periodicos.ufsc.br/index.php/fisica/article/view/6055/12760>. Acesso em: 20 dez.2007.

LANGHI, R. \& NARDI, R. A Educação em Astronomia nos anos iniciais do Ensino Fundamental: identificando algumas trajetórias formativas de professores. In: ENCONTRO NACIONAL DE DIDÁTICA E PRÁtICA DE ENSINO, 14, Porto Alegre, 2008. Anais... Porto Alegre: PUCRS, 2008.

LANGHI, R. \& NARDI, R. À procura de um programa de educação continuada em Astronomia adequado para professores dos anos iniciais do ensino fundamental. In: ENCONTRO DE PESQUISA EM ENSINO DE FÍSICA, 11, Curitiba, 2008. Caderno de resumos... Curitiba: SBF/UFTPR, 2008a.

LANGHI, R. \& NARDI, R. Ensino da astronomia no Brasil: educação formal, informal, não-formal e divulgação científica. Revista Brasileira de Ensino de Física, v. 31, n. 4, p. 4402-1 a 4402-11, 2009. 
Disponível em: < http://www.sbfisica.org.br/rbef/pdf/314402.pdf>. Acesso em: 20 dez. 2009. LATTARI, C.J.B.; TREVISAN, R. H. Implantação de Astronomia em currículo básico do curso de ciências. In: SIMPÓSIO NACIONAL DE ENSINO DE FÍSICA, 11, Niterói, 1995. Atas... Rio de Janeiro: SBF, UFF, 1995. p. 166-169.

MACIEL, W. J. et al (org). Astronomia e astrofísica. São Paulo: IAG/USP, 1991.

MALUF, V. J. A Terra no espaço: a desconstrução do objeto real na construção do objeto científico. Dissertação de Mestrado. Cuiabá, UFMT, 2000.

MARRONE JÚNIOR, J. Um perfil da pesquisa em ensino da Astronomia no Brasil a partir da análise de periódicos de ensino de ciências. 253f. Dissertação (Mestrado em Ensino de Ciências e Educação Matemática), Universidade Estadual de Londrina, Londrina, 2007.

MIZUKAMI, M. G. N. et al. (org) Formação de professores: tendências atuais. São Carlos: EdUFSCar, 1996. MIZUKAMI, M. G. N. et al. (org) Escola e aprendizagem da docência: processos de investigação e formação. São Carlos: EdUFSCar, 2002.

MOURÃO, R. R. F. Atlas celeste. $8^{\text {a }}$ ed. Petrópolis: Vozes, 1997.

NARDI, R. \& CARVALHO, A.M.P. Um estudo sobre a evolução das noções de estudantes sobre o espaço, forma e força gravitacional do planeta Terra. Investigações em Ensino de Ciências, 1(2):20-39, 1996.

NUSSBAUM, J. Children's conceptions of the earth as a cosmic body: a cross age study. Science Education, 63(1), p. 83-93, 1979.

NUSSBAUM, J. \& NOVAK, J. D. An assessment of children's concepts of the Earth utilizing structured interviews. Science Education, 60 (4), p. 685-691, 1976.

OSBORNE, R. e WITTROCK, M. The generative learning model and its implications for science education. Studies in Science Education, v. 12, p. 59-87, 1985.

OSTERMANN F. \& MOREIRA, M. A. A física na formação de professores do ensino fundamental. Porto Alegre: Ed. Universidade/UFRGS, 1999.

PACHECO, J. A. B. Formação de professores: teoria e práxis. Portugal: Appacdm, 1995.

PEÑA, B. M. \& QUILEZ, M. J. G. The importance of images in astronomy education. International Journal of Science Education, v. 23, n. 11, p. 1125-1135, 2001.

PIETROCOLA, M. Construção e realidade: o papel do conhecimento físico no entendimento do mundo. In: PIETROCOLA, M. (org.) Ensino de física: conteúdo, metodologia e epistemologia em uma concepscão integradora. $2^{\mathrm{a}}$ ed. Florianópolis: Editora da UFSC, 2005.

PIMENTA, S. G. (org). Saberes pedagógicos e atividade docente. $2^{\mathrm{a}}$ ed. São Paulo/BRA: Cortez, 2000.

PORLÁN, R. \& RIVERO, A. El conocimiento de los profesores. Una propuesta formativa em el área de ciencias. Espanha: Diada Editora, 1998.

SAB - SOCIEDADE ASTRONÔMICA BRASILEIRA. Olimpiada brasileira de Astronomia. Disponível em: <http://www.oba.org.br>. Acesso em: 30 março 2009.

SAMPAIO, M. M. F. Um gosto amargo de escola. Relações entre currículo, ensino e fracasso escolar. São Paulo: Educ/FAPESP, 1998.

SÃO PAULO. Secretaria de Estado da Educação. Concurso público para provimento de cargos de professor educação básica II. Boletim informativo. Disponível em: < http://www.sepeb2.com.br>. Acesso em: 10 outubro 2003.

SBPC - SOCIEDADE BRASILEIRA PARA O PROGRESSO DA CIÊNCIA. Cosmologia ao alcance de todos. JC e-mail 2763, São Paulo, 09 maio 2005. Disponível em: < http://www.jornaldaciencia.org.br>. Acesso em: 09 maio 2005.

SCALVI, R. M. F. et al. Abordando o ensino de óptica através da construção de telescópios. Revista Brasileira de Ensino de Física, v. 28, n. 3, São Paulo: SBF, 2006.

SEBASTIÁ, B. M. Investigación didáctica en astronomía: una selección bibliográfica. Enseñanza de las Ciencias, v. 13 (3), p. 387-389, 1995.

SHULMAN, L. Knowledge and teaching: foundations of the new reform. Harvard Education Review, 57 (1), p. 1-22, 1987.

STAHLY, L. L. et al. Third grade students' ideas about the lunar phases. Journal of Research in Science Teaching, v. 36, n. 2, p. 159-177, 1999. 
TARDIF, M. Saberes docentes e formaşão profissional. $4^{a}$ ed. Petrópolis: Vozes, 2004.

TIGNANELLI, H. L. Sobre o ensino da Astronomia no ensino fundamental. In: WEISSMANN, H. (org.). Didática das ciências naturais: contribuições e reflexões. Porto Alegre: Artmed, 1998.

TRUMPER, R. A cross-age study of junior high school students' conceptions of basic astronomy concepts. International Journal of Science Education, v. 23, n. 11, p. 1111-1123, 2001.

VOSNIADOU, S. \& BREWER, L. Mental models of the daylight cycle: a study of conceptual change in childhood. Cognitive Psychology, 24: 535-585, 1992.

ZEILIK, M. Misconceptions and their change in university-level astronomy courses. The Physics Teacher, v. 36, p. 104, fev. 1998. 